\title{
State management of the national food security in Vietnam
}

\author{
Minh Duc Tran ${ }^{1, *}$ \\ ${ }^{1}$ Graduate Academy of Social Sciences, Nguyen Trai Street, No. 477, Thanh Xuan District, Ha Noi, \\ 10000, Vietnam
}

\begin{abstract}
Ensuring national food security for the present and future under any circumstance is a current urgent and complicated issue in Vietnam in the context of climate change, disease and in the process of striving Vietnam to become an industrialized country towards modernization. Ensuring food security has become a legal issue for every country, including Vietnam. To ensure national food security, there is a need for a state management. Therefore, this paper focuses on analyzing the status of regulations and applying the law in a state management of food security. Based on a comparison with the achievement of the goal of national food security in Vietnam, the article points out some of the current limitations and shortcomings in the State management of food security; then, proposes some solutions to improve the efficiency of the state management in this area, including: good management of planning production land for food; improve the state management apparatus of the national food security; increasing investment in infrastructure and scientific research serving food production; review the role and effectiveness of each stage in the food production value chain; improve policies to ensure a reasonable and stable profit for people who producer, storage, process and distribute food.
\end{abstract}

\section{Introduction}

Food security in the conventional sense is the approach of people to food for healthy living at all times. The concept of food security is used at many different levels: individual, household, local, national and global [5]. Food security is always a very important issue for all countries, especially in the context of political instability, non-traditional security and epidemics in the world.

It can be said that food security is a big and complex issue. It involves many aspects of life and society. A national food security should be linked to a food security of every citizen. To ensure food security for all households, it needs to have sufficient food; access to that source of food; that food must be in accordance with cultural tradition of the households; hence, the households will not be vulnerable to shocks. Food security is both stable and equitable [5].

As the subject of public power, the role of state management of food security is very important, the content of state management of food security is the overall program of action

*Corresponding author: tranminhducdanang@gmail.com 
of the State to create a change in the quantity, quality and food structure suitable to each stage of socio-economic development at different levels of the country and region, in order to achieve the objectives on food and to contribute to sustainable development of society.

In Vietnam, the Party and the Government always care the national food security. The Government issued the Resolution No. 63/NQ-CP on December 23th, 2009, stating clearly the objective "By 2020, vision by 2030, must ensuring adequate food supplies with output higher than the population growth rate; ending food shortages, improve meal quality; ensuring an average profit of over $30 \%$ compared to production costs for rice farmers".

In fact, over the past time, ensuring food security has made some progress in food production, nutritional needs and ensuring access of people to food. However, food security in Vietnam is still limited and inadequate, as the National Online Conference on March 18th, 2020 summarising 10 years of implementing Conclusion 53 of Politburo of the project "National food security until 2020", Prime Minister Nguyen Xuan Phuc stated that "Vietnam exports food in the top of the world but the food security ranks only 57/113 countries - the middle level. Regarding rice cultivation, living standards of farmers have been improved but many are still poor and difficult..." [1]. This indicates that there are many things needed to be improved regarding the food security in Vietnam, including the state management of the food security.

Based on the above reasons, this article examines the situation of contents of the state management and of the implementation of national food security goals in Vietnam. This is to point out solutions that contribute to improve efficiency of the state management of food security in Vietnam.

\section{Materials and research methods}

The author has used the analytical method to analyse current national food security legislation in Vietnam; using methods of analysis, integrated and statistical methods to make assessments of legal provisions and application of laws on the content of state management on the national food security. Based on the analysis of laws and researching articles, reports and data related to the national food security, the author makes recommendations that contribute to improving the efficiency of the state management of food security in Vietnam at present.

\section{Research results}

\subsection{Situation of content of state management of food security in Vietnam}

Firstly, the State issues orienting documents and creates a legal framework for the national food security.

At the national level, Vietnam has issued strategic documents on food security, such as the Conclusion No.53-KT/TW of Politburo on August 5th, 2009 on the National Food Security Scheme up to 2020 states: Food security is an important issue of the country in the short and long term. In the upcoming development, the following major issues need to be paid attention: i) Planning comprehensive and effective agricultural production development is the basis for firmly ensuring national food security; associating production with appropriate organisational forms to meet fully and promptly food needs in all circumstances; raising nutrition and improving meals of the people; ii) Promoting the advantages of rice as the main crop and developing food and foodstuffs into areas of commodity production with high efficiency and competitiveness; promoting mechanisation, processing and preservation in the direction of industrialisation, modernisation and 
sustainable environmental protection; iii) Harmonious balance between domestic consumption and export of food; organising well the system of buying, selling and storing in regions, creating favorable conditions for people to access easily food and foodstuffs with increasing quality and efficiency; iv) targeting up to 2020, a vision toward 2030, to ensure adequate food supply with an output of more than 2 times the population growth rate; terminating food shortage, improving meal quality; ensuring profit of over $30 \%$ of production cost for rice farmers.

On the basis of the orientation of the Politburo according to the conclusion No. $53 \mathrm{KT} / \mathrm{TW}$ on food security, the Government issued Resolution No. 63/NQ-CP on December 23th, 2009, on national food security assurance. The views on the national food security of the Vietnamese Government are consistent with the developmental trend of the country with five major perspectives throughout:

i) It has been pointed out clearly that the national food security cannot stand independently but must be in the overall socio-economic developmental strategy linked to the goals of national industrialisation and modernisation and solve agricultural, farmer and rural issues, in which hunger eradication and poverty reduction, job creation and income generation for the people are important, contributing to ensuring firmly the national food security;

ii) The basis for ensuring the national food security is developing a comprehensive and efficient agricultural production; associating production with appropriate organisational forms to meet fully and promptly food needs in all circumstances; improve the nutrition and quality of meals of people;

iii) Based on the strength of rice production and the high rice-consumption culture of Vietnamese people, the Government has selected and identified a key crop to ensure food that is promoting the advantage of rice and developing food and foodstuffs of commodity production with high efficiency and competitiveness by regions; promoting mechanisation, processing and preservation toward industrialisation, modernisation and sustainable environmental protection;

iv) To ensure food security for all people, it is necessary to well organise the system of buying, selling and storing in regions, creating favorable conditions for people to access easily food and foodstuffs with the increasing quality and efficiency; to harmonise domestic consumption and export of food and foodstuffs;

v) Vietnam has also defined clearly the role of the State, businesses and people in ensuring food security. In particular, they are promoting the main resources of the people and the economic sectors, and the state supports actively in ensuring the national food security, ensuring income for food producers and creating developmental conditions for purely agricultural localities.

Based on the above points of view, the Resolution 63/NQ-CP of the Government of Vietnam, with an approach to the food security associated with lives of people, has set specific goals for the food security in three aspects, that is to ensure the food supply; ensure the nutritional needs; ensure the access to food of people.

Secondly, organisining the implementation of the national food security legislation.

The organisation of implementation of the national food security legislation is particularly important, because it is a step to actualise the law on the national food security; the results of the implementation of the law on the food security will define if the policies and laws are right, appropriate and able to put into practice; the process of implementation of the national food security legislation with practical activities will contribute to the adjustment, supplementation and completion of policies and laws to suit and meet the requirements of the reality. Specifically, the situation of organising the implementation of the law on the national food security is:

i) Implementation and coordination among state agencies, organisations and individuals 
involved in the implementation of the national food security legislation: The Resolution 63 in 2009 of the Government clarifies the tasks and solutions that need to be done to implement the objectives of the national food security scheme, corresponding to each specific task, and those from central to localities based on functions and tasks to perform, for example: i) Regarding rice land planning, the Ministry of Agriculture and Rural Development coordinates with the Ministry of Natural Resources and Environment and the provincial-level People's Committees in directing the detailed planning of rice land fund. Provincial-level People's Committees bases on the approved national rice land planning, determine the rice areas to be kept in their localities, makes maps for communes and households. ii) Regarding infrastructure development, it is implemented by the Ministry of Agriculture and Rural Development and the provincial People's Committees in coordination with the relevant ministries and branches. iii) Regarding development and application of science and technology: The Ministry of Agriculture and Rural Development, the Ministry of Science and Technology coordinate with the provincial People's Committees, give priority to the development and application of science and technology in a number of fields related to food production and processing;

Thus, the state management system of food security is gradually improved from the central to local levels, in order to enhance the coordination between state management agencies on the food security. However, the implementation of the state management function on the food security is fragmented between state management agencies and managing agencies, between specialised ministries and localities.

ii) Training human resources for the implementation of the national food security legislation.

Training human resources related to food security is a very broad issue, requiring many resources. Resolution No. 63 of the Government has assigned specific ministries: the Ministry of Agriculture and Rural Development, the Ministry of Labor - Invalids and Social Affairs, the Ministry of Education and Training in coordination with the provincial People's Committees implement effectively the Vocational Training Program for agricultural and rural workers; the targets of training and content of training are: Firstly, training and improving the capacity of the contingent of scientific and technical staffs, agricultural extension workers and food production and business management officers at all levels; bringing national food security content into schools. Secondly, strengthening training of farmers in science and technology and management knowledge in the appropriate method to improve the efficiency of food production and increase income.

Human resource training in agriculture and agricultural vocational training for rural workers have been promoted. Over the past 10 years, the country has trained 9.6 million rural workers. After apprenticeship, $90 \%$ of the workers have a new job or continue an old job with a higher income [1].

iii) Regulating development of food through specific policies.

In addition to planning land for food production, developing infrastructure and science and technology and developing information systems of food security, the State also regulates food development by specific policies, such as: a) Encouraging farmers to keep rice land by implementing synchronously measures to reduce production costs, increase incomes for rice producers, ensuring a profit of over 30\% compared to the input price for rice producers; implementing continuously policies to support farmers in building terraced fields in mountainous areas; b) Encourage localities to keep rice land in the direction of increasing development and investment for agriculture and rural areas; regulating the allocation of state budget to ensure benefits between localities with industrial development conditions and purely agricultural ones, especially specialising in rice cultivation; c) Encourage enterprises to consume rice via mechanisms and policies supporting investors to build rice warehouses, with a total volume of 4 million tons of food storage planned to 
reduce post-harvest losses on agricultural and aquatic products and ensure the national food security; to adopt mechanisms and policies to support enterprises in performing the task of consuming rice assigned by the State in case the rice price falls below the input price; d) Implementing the rice support policy for people in areas suffering from hunger due to natural disasters and epidemics; completing the rice subsidy policy for local ethnic minority households in mountainous areas to plant forests for replacement of upland fields cultivation.

iv) Carry out activities to ensure and protect the law on the food security

Resolution No. 63/NQ-CP of the Government in 2009 also stipulates clearly responsibilities in ensuring the organisation of the implementation of the national legislation on food security, namely:

Firstly, the Ministry of Agriculture and Rural Development is responsible for coordinating with ministries, branches and provincial-level People's Committees in organising specific activities, guiding the implementation, guiding inspection and supervision and periodically report to the Prime Minister on the situation of implementation of the national food security.

Secondly, ministries and branches base on their functions and tasks to implement the domains in charge of the food security assurance according to the contents of this Resolution.

Thirdly, provincial-level People's Committees formulate and approve the planning of development of food production by industry in their localities; manage strictly the fund of agricultural production land, especially planned rice land; implement well mechanisms and policies of the State on food production and consumption; supplement the local mechanisms and policies to suit practical conditions; encourage the development of production to ensuring the national food security in all situations.

\subsection{The situation of implementing national food security goals in Vietnam}

Firstly, implementing the goals of ensuring food supply.

The Resolution No. 63/NQ-CP of the Government in 2009 set the goal of ensuring the food supply: "By 2020, protecting the rice land fund of 3.8 million hectares so as to have an output of 41-43 million tons rice and meet the total domestic demand and about 4 million tons of rice per year for exports; increasing the area of maize cultivation to 1.3 million hectares and the output of 7.5 million tons; area of fruit trees is 1.2 million hectares and an output of 12 million tons; 1.2 million hectares of vegetables with 20 million tons of output; output of crops increased by over 30\%; livestock production reaches 8 million tons of pork (live weight), 1 million tons of fresh milk, 14 billion eggs of poultry; fishing production is 2.4 million tons and aquaculture production is 4 million tons".

In order to stabilise the food supply, Vietnam has implemented simultaneously solutions from planning agricultural land, developing infrastructure and science and technology in the field of agriculture, implementing incentive policies to farmers and businesses participating more deeply in the agricultural sector. In Vietnam, there are currently 15,300 agricultural cooperatives and 12,600 enterprises investing in agriculture and accompanying farmers in food production, processing and distribution. The review of 10 years of implementation of the project on "National food security to 2020" at the National Online Conference on March 18th, 2020 evaluated that the food production in Vietnam after 10 years of implementing the Project on food security has achieved many positive results. Specifically, the criteria on ensuring food supply have reached and exceeded the targets set for 2020, in which it is noticeable that the rice land area of the country in 2018 reached over 4,159 million hectares (the set target was 3.8 million hectares); Rice production in 2019 reached 43.4 million tons (the target was set at 41-43 million tons); Rice exports in 2019 
reached 6.34 million tons (the target was set at 4 million tons).

Agriculture has a relatively high growth rate (reaching $2.61 \%$ /year). Rice productivity of Vietnam is the highest in Southeast Asia, reaching 5.6 tons/ha, nearly double of Thailand and 1.5 times higher than India; coffee productivity is 1.5 times higher than Brazil, 3 times higher than Colombia and Indonesia; pepper productivity is 3 times higher than Indonesia and 1.3 times higher than India; Pangasius catfish productivity averaged 209 tons/ha, the highest in the world [1].

The value and output of many agricultural products increased sharply (in the period of 2009 and 2019, the food per capita increased from $497 \mathrm{~kg} /$ year to over $525 \mathrm{~kg} /$ year; the output of vegetables grew rapidly by $80.5 \%$, from 9.75 million tons to 17.6 million tons; fruit production increased from 6 million tons to 12.6 million tons). Export of agricultural products continues to be promoted, with 7 items with export turnover of over 1 billion USD/year; an average annual export of 5-7 million tons of rice [1].

Although Vietnam is able to ensure food self-sufficiency with a relatively high average food output per capita (ranked 6th in the world) [1] and ranks among the top in the world in terms of food, but food security ranks only 57th out of 113 countries - the middle level. Chain production linkages associated with area of production, processing and market organisation are generally weak in all sectors [1]. Labor productivity in agriculture is low due to small and fragmented production. The application of mechanisation and automation has a low rate, making the price high and difficult to compete.

Secondly, ensuring the nutritional needs: The goal of ensuring the nutritional needs under Resolution 63 is: "By 2020, it improves the nutritional status towards balanced nutrition, improves the daily average consumption of calorie to 2,600 - 2,700 Kcalo/person and reduces the rate of malnutrition of under-5-year-old children to less than $5 \%$. Improving the structure and quality of food consumption, reaching an average consumption per person by 2020: rice reduces to $100 \mathrm{~kg}$, meat reaches $45 \mathrm{~kg}$, fish reaches $30 \mathrm{~kg}$, fruit reaches $50 \mathrm{~kg}$, vegetables reaches $120 \mathrm{~kg}$, increasing the consumption of eggs and milk 2 times higher than the present. All agricultural products and foodstuff consumed in the market meet the criteria of food hygiene and safety".

Along with the incentive mechanism and policies for investments in the agricultural sector, many models of clean agricultural production, hi-tech applications and organic agriculture have been developed and invested, contributing to maintain macroeconomic, job creation, poverty reduction.

In Vietnam, the propaganda and orientation of nutrition in the meals for people is increasingly focused, the nutritional deficiency is significantly reduced, from over $18 \%$ of the previous period to nearly $11 \%$ at present. The amount of rice eaten per capita decreased from $132 \mathrm{~kg}$ in 2008 to nearly $97 \mathrm{~kg}$ in 2018 . Remarkably, also at these times, while reducing the consumption of rice, the amount of meat eaten per capita increased from $17 \mathrm{~kg}$ to $26 \mathrm{~kg}$ [1].

However, the process of implementing this goal is limited, not to mention the structure of foods that contribute to improving health and race, such as the need to increase rapidly the production of eggs, chicken, seafood, vegetables and fruit that is healthy and suitable for the nutrition structure; reducing the production rate of high-consumption unhealthy foods.

Thirdly, ensuring the access of people to food: The goal under the Resolution 63 of the Government in 2009 is "By 2020, terminating the food shortage in 2012. After 2012, ensure $100 \%$ of people have enough food at everywhere, anytime. Ensuring income for food producers by 2020 is 2.5 times higher than the present".

In recent years, Vietnam has promoted the implementation of new rural programs; agricultural restructuring; poverty reduction programs have promoted production development, job creation, income generation, improved living conditions for poor, near- 
poor and newly-escaped-poor households contributing to improve income, develop economy and reduce poverty. Income per capita has continuously increased in Vietnam, helping to improve food access In particular, the average monthly income per capita increased from 356,100 VND in 2002 to 3.76 million VND in 2018 [9].

In the period of 2009 and 2019, the income per capita in rural areas has increased by 4.3 times, income gap between urban and rural areas had narrowed from 2.1 times to 1.8 times [1], profits of rice farmers reached at least $30 \%$ of the production costs.

In fact, the income from agricultural production in Vietnam has increased compared to the past but it is not high and not sustainable. Typically, the situation of "good harvest devaluation" and rescue of agricultural products is common and popular. Impacts of climate change, sea level rise, salinisation, drought, floods threaten seriously food production, especially in the Mekong Delta, which also seriously affects rice production as well as agriculture. The living standards of Farmer have been improved but many people have been poor and facing difficulties. Therefore, it is necessary to restructure agriculture and produce food in a reasonable way to improve the lives of farmers [1].

\subsection{Some issues and solutions to improve the effectiveness of state management of the national food security in Vietnam}

Firstly, it is necessary to well manage the planning of food production land to ensure the food security for the present and future.

In principle, the national food production planning must be based on promoting the advantages of each region and each type of food to use resources effectively; the food production planning must ensure a harmonious balance between ensuring the national food security and economic efficiency. In fact, there is complex issue of planning food production land Vietnam currently. There are many questions: How much retain rice and agricultural land is appropriate? If the output meets domestic demand and is surplus, then, it can export, but if the food is exported, how far will it be more efficient than using that land to develop other industries?

In general, domestic demand for food and foodstuffs will change due to the population growth. According to forecast of the General Statistics Office of Vietnam, Vietnamese population will reach about 103 million people by 2030. The demand for rice in the meal structure decreases, the demand for meat, fish, eggs, milk, vegetables increases. According to estimates by the Institute of Policy and Strategy for Agricultural and Rural Development, the demand for rice per capita of Vietnam by 2025 is only $93.7 \mathrm{~kg} / \mathrm{person} / \mathrm{year}$ and by 2030 is only $93.3 \mathrm{~kg} /$ person/year. There should be a view that a part of rice land should be gradually shifted to fruit and vegetable production, animal husbandry and aquaculture development to meet the consumption structure of the demand for domestic food and foodstuff [9]. However, this is only a view on domestic food demand. Currently, in Vietnam, the amount of rice land is 4,159 million hectares. As the leading rice exporter in the world, it is necessary to consider the conversion of rice land area to produce other kinds of food with more effective, or maintaining the land area of paddy land, both satisfying domestic demand and being able to export at high economic value. In the short term, it is recommended to allow the conversion of a part of inefficient area of rice cultivation to other crops and livestock, increasing the income of farmers. In the long run, food products need to shift the strategy gradually from the food security to the nutritional security, gradually reducing the rate of rice use per capita in Vietnam, which means Vietnam will reduce the pressure on the rice production [4] and rice exports are no longer the top targets if its economic efficiency is not high. Rice land (not necessarily only the inefficient land) is converted to other crops and livestock with the principle that the converted area can be reused to grow rice if it is required. 
Secondly, completing the state management apparatus of the national food security. Currently, in Vietnam, there are many state agencies implementing the law on the national food security but sometimes their functions and duties are overlapping. For instance, the rice export of Vietnam is mainly managed by the Ministry of Industry and Trade but the consumption and circulation of rice are mainly done by farmers and businesses; agricultural land is managed by the Ministry of Natural Resources and Environment; rice production is managed by the Ministry of Agriculture and Rural Development; vocational training for rural workers is a matter of the Ministry of Labor - Invalids and Social Affairs. Therefore, it leads easily to the inconsistency of the executive management of food security, as in March, 2020, by the Ministry of Industry and Trade has suggested to the Government to export rice whilst the covid-19 epidemic was happening globally with contradictory content (it allowed and it did not allow repeatedly). This because they do not know the data on the amount of rice in stock, the amount of exported rice, the amount of export contracts in Vietnam leading to the Permanent Government must meet on March 31st, 2020 to carefully consider whether rice should be exported in the context of the Covid-19 epidemic as well as the context of drought and salinisation in Vietnam. Therefore, it is necessary to improve the state management apparatus for ensuring food security, with the principle of "one thing must have a main responsible agency", with clear and non-overlapping functions. It is thought that a National Food Security Committee should be established to act as the main focal point for the research, proposal and implementation of the national food security enforcement policies to ensuring the consistency and accuracy, also ensuring the national food security and promoting agricultural advantage of Vietnam.

Thirdly, increasing infrastructure investment and scientific research for food production.

Agricultural production of Vietnam is heavily depending on the weather, and the impact of climate change makes it difficult to manage and organise the implementation of the food production planning. Agricultural infrastructure is inadequate compared to the requirements of centralised commodity production and international competition, so as it is necessary to continue developing infrastructure, science and technology in agricultural production to mitigate the impact of climate change and improve international competitiveness. Therefore, it is necessary to modernise the irrigation system for food production areas suitable to the delta and mountainous areas; to develop modern processing technology, with advanced technology; convenient and efficient transportation and distribution system of food products for the domestic and export markets. It is necessary to make adequate investments in research and technology transfer for people and production facilities, such as focusing on research and transfer of high-yield and high-quality food crops suitable to each area, meeting market requirements, research and transfer of advances in cultivation, harvest, storage and processing measures. The development of infrastructure and the transfer of science and technology should link the interests of relevant individuals and organisations based on the basis of promoting the human resources of the people and all economic sectors; the State should promulgate mechanisms and policies to encourage and support investment in infrastructure development and science and technology transfer.

There is a need to change the perception of food security which is focusing not only on availability, accessibility, and payment but also on ensuring nutrition and food safety.

Fourthly, it is necessary to review the role and effectiveness of each stage in the food production value chain.

Currently, in Vietnam, the household economy accounts for a large proportion in the food production. The scale of a household production is small (the average is only 0.18 ha/land plot and 2.5ha/land plots/household) [9]. Vietnam currently has 15,300 agricultural cooperatives and 12,600 enterprises investing in agriculture [1], although there has been an increase in recent times, they are small scale, low financial capacity, and low operational efficiency; the linkage between farmers and rice exporters is still fragmented. 
The processing industry is not synchronised, the post-harvest losses are large. For example, the post-harvest losses in rice in the Mekong Delta are sometimes up to 30\% [4]. Therefore, it is necessary to renovate and develop forms of production organisation to meet the requirements of a large and concentrated commodity production, to avoid post-harvest losses. Mechanisms and policies are needed to build an effective link from production, processing to food distribution.

The linkage in food production and distribution must be oriented by the State. It is necessary to have a horizontal link between producers to avoid production fragmentation, which will accumulate land, unify farming methods, and form large farms, specialised areas for cultivating food crops. This will create conditions to use mechanisation, apply new scientific achievements, and unify plant varieties to achieve uniform product quality, increase productivity, and reduce costs in food production. Vertical link to connect production, processing and business to increase value and reduce operating costs [10]. Therefore, horizontal and vertical connections need to be strengthened further.

Fifth, completing policies to ensure people who produce, storage, process and distribute food have a reasonable and stable profit level.

In fact, food production is at risk easily due to natural disasters and price fluctuations. But at present, Vietnam has not had a comprehensive policy for food producers to have a stable and balanced income compared to other industries. At a time when prices were low, production was at a loss and farmers had to abandon their fields to other works. Therefore, the State should stipulate that purchasing price of rice is not lower than a certain minimum level. During the harvest, the State can support low interest rates of loans for a certain period of time for food companies to buy rice from farmers in a timely manner, to avoid falling prices [11]; there should be a policy to encourage food companies to order food from farmers at the beginning of the season of crops and to assist farmers in food production activities. It is necessary to create a transparent trading environment to eliminate the situation of buying rice through many intermediaries, which easily leads to farmers being forced to sell as a low price but the price to consumers is high.

\section{Conclusion}

Based on the research results, it can be conclude as follows:

Firstly, the state management of the national food security plays a very important role in ensuring food supply; ensuring nutritional needs; ensuring access of people to food. Facing the situation of a problem of the national food security is increasingly complicated by the situation of the Covid-19 epidemic, global warming and the development of industrialisation in Vietnam. Therefore, it is necessary to complete the state management of the national food security in Vietnam.

Secondly, Vietnam has defined clearly the goals of food security to achieve at the present and in the future. This has made the state management of the food security more coherent. However, food security is a great national concern and is closely linked to the lives of people. This is always affected by objective and subjective factors, so the process of regulating the contents of state management and organising the implementation has many shortcomings that need to be removed to contribute to improving the efficiency of the state management of the national food security. 


\section{References}

1. The report at the National Online Conference summarising 10 years of implementation of the Conclusion 53 of the Politburo of the Project "National Food Security to 2020" (The Ministry of Agriculture and Rural Development, 2020)

2. S.C. Nguyen, Firuges \& Events Review 5, 17-19 (2013)

3. N.D. Vu, V.C. Nguyen, Journal of Scientific Activities 8, 13-14 (2008)

4. V.D. Nguyen, Journal of Scientific Activities 10, 16-21 (2016)

5. H.H. Tran, Journal of Ethnography 1\&2, 18-30 (2009)

6. Minh Hoai, Journal of Political Theory 5, 60-68 (2009)

7. M.H. Nguyen, Communist Review 790, 60-64 (2008)

8. H.K. Nguyen, State Organisation Research Journal 10, 20-23 (2008)

9. T.N.L. Nguyen, Financial Magazine 1, 55-59 (2019)

10. Q.L. Tran, Economic and forecast magazine 3, 22-24 (2009)

11. V.S. Ha, Social and economic magazine 2, 84-87 (2010) 